\title{
RAND HEALTH
}

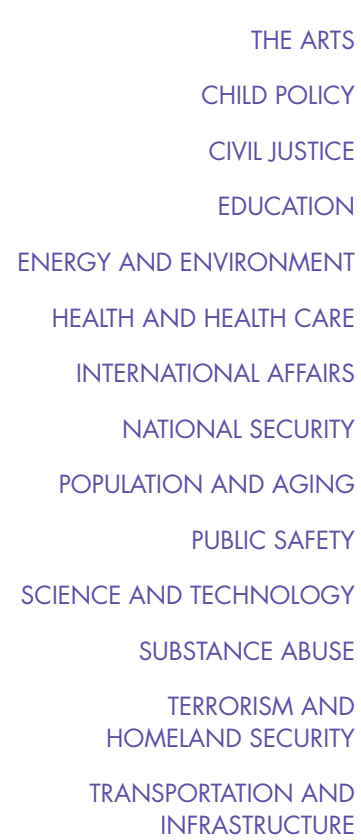

WORKFORCE AND WORKPLACE
This PDF document was made available from www.rand.org as a public service of the RAND Corporation.

Lump down to document $\nabla$

The RAND Corporation is a nonprofit research organization providing objective analysis and effective solutions that address the challenges facing the public and private sectors around the world.

\section{Support RAND \\ Browse Books \& Publications \\ Make a charitable contribution}

\section{For More Information}

Visit RAND at www.rand.org

Explore RAND Health

View $\underline{\text { document details }}$

This product is part of the RAND Corporation reprint series. RAND reprints present previously published journal articles, book chapters, and reports with the permission of the publisher. RAND reprints have been formally reviewed in accordance with the publisher's editorial policy, and are compliant with RAND's rigorous quality assurance standards for quality and objectivity. 


\section{Improving Care for Depression in Patients With Comorbid Substance Misuse}

\author{
Katherine E. Watkins, M.D., \\ M.S.H.S. \\ Susan M. Paddock, Ph.D.
}

Lily Zhang, M.S.

Kenneth B. Wells, M.D., M.P.H.
Objective: The authors investigated whether quality improvement programs for depression would be effective among substance misusers and whether there would be a differential program-by-comorbidity effect.

Method: A group-level randomized controlled trial (Partners in Care) compared two quality improvement programs for depression with usual care. Consecutive patients $(\mathrm{N}=27,332)$ from six managed care organizations in five states were screened, and 1,356 were enrolled: 443 received usual care while the rest entered a quality improvement program involving either medication $(\mathrm{N}=424)$ or therapy $(\mathrm{N}=489)$. Multiple logistic regression was used to test hypotheses and compute standardized predictions of the adjusted rates of depression and use of psychotherapy and antidepressants.

Results: Under usual care conditions, depressed patients with substance misuse had an increased probability of ongoing depression despite higher rates of overall appropriate treatment. Among clients with comorbid substance misuse, the quality improvement programs were associated with improved depression outcomes at 12 months and increased antidepressant use at 6 months. Among clients with no substance misuse, the quality improvement programs improved depression outcomes at 6 months and were associated with increased treatment utilization.

Conclusions: Co-occurring substance misuse is associated with depression and with increased risk for poorer depression treatment outcomes under usual care conditions. Quality improvement programs can significantly reduce the likelihood of probable depressive disorders in depressed patients with and without comorbid substance misuse. No consistent evidence was found for a differential program-by-comorbidity effect except for a suggestion of greater increase in psychotherapy among individuals with no substance misuse.

(Am J Psychiatry 2006; 163:125-132)

S ubstance misuse is common among people with depressive disorders, and the co-occurrence of substance misuse and depression is associated with greater impairment and worse treatment outcomes than in individuals with either disorder alone (1-6). National data suggest that among individuals with an episode of major depression in the past year, $21 \%$ had an alcohol use disorder and $9 \%$ had a drug use disorder; many more have substance misuse but not abuse or dependence $(7,8)$. Among primary care patients with depression, more than one-quarter report substance misuse; some of these have abuse or dependence (9). The quality of care for co-occurring disorders is low, and the majority of people with co-occurring disorders do not receive either mental health or substance abuse care $(10,11)$.

The quality of care for depressive disorders can be improved by practice-based quality improvement interventions that lead to increased rates of treatment and improved clinical outcomes $(12,13)$. These interventions work in primary care settings among clients with and without comorbid medical illnesses (14) and among men and women (15), but it is not known whether such pro- grams are effective for individuals with depression and substance misuse.

There are several reasons to suspect that a quality improvement intervention might have a different effect among individuals with co-occurring substance misuse. The presence of comorbid substance misuse complicates the diagnosis and treatment of depression, with some experts recommending psychotherapy and a period of abstinence before initiating pharmacotherapy, whereas others offer antidepressant treatment to clients even when substance use is ongoing (16-18). Treatments for depression are thought to be less effective among substance users (4), although some studies suggest that treatment is effective even among those who use alcohol (19) or other drugs (20, 21). Patterns of care may also differ, since 1) providers may be more likely to provide psychotherapy than medication to depressed patients with co-occurring substance misuse, and 2) behavioral treatments carry little or no risk to the patient and can be initiated early in treatment when a formal diagnosis of depression is still uncertain (22-24).

We used data from the Partners in Care trial to investigate whether quality improvement programs for depres- 
FIGURE 1. Patient Progression Through Partners in Care ${ }^{a}$

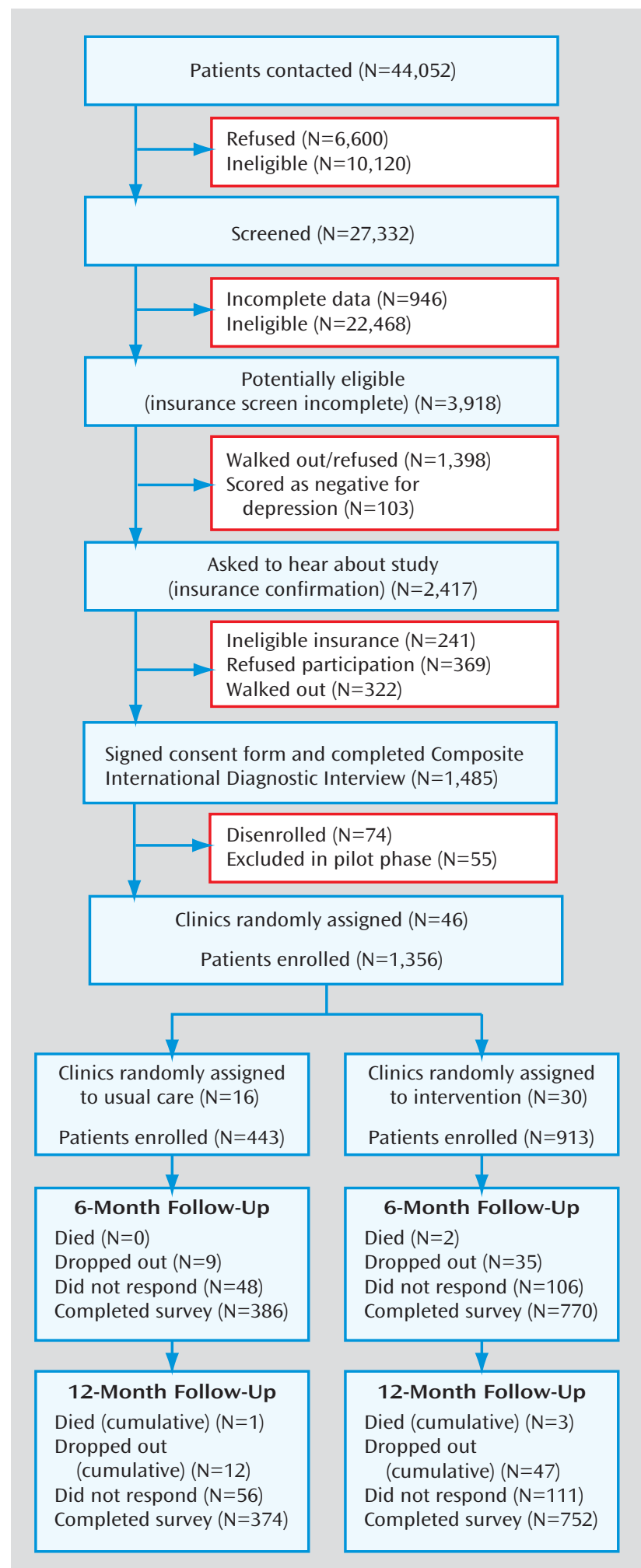

a A group-level randomized controlled trial involving six managed care organizations in five states that compared two quality improvement programs for depression with usual care.

sion would be effective among substance misusers (25). We hypothesized that 1) under usual care conditions, de- pressed primary care patients with comorbid substance misuse would have a higher probability of ongoing depression, lower rates of antidepressant use and overall appropriate treatment, and higher rates of psychotherapy at 6 and 12 months than patients without comorbid substance misuse; and 2) quality improvement programs for depression would be effective among substance abusers as well as nonusers and would improve rates of overall appropriate treatment.

\section{Method}

\section{Study Design}

Partners in Care was a group-level, randomized controlled trial involving six managed care organizations in five states that compared two quality improvement programs for depression with usual care. It included staff and network model multispecialty group practices and rural managed public health clinics; patients had prepaid or managed fee-for-service coverage. Clinics were selected to oversample Mexican Americans and to be diverse in geography and organization (25). Forty-six of 48 primary care clinics participated, and 181 of 183 primary care providers agreed to participate. Forty-six clinics were grouped into nine blocks of three clinic clusters each, matched for patient demographics, clinician specialty, and proximity to a mental health provider. Within each block, clinics were randomly assigned to provide usual care or one of two quality improvement interventions (medication or therapy).

As seen in Figure 1, study staff screened 27,332 consecutive patients over a 57-month period between June 1996 and March 1997. Patients were eligible if they intended to use the practice for 12 months and screened positive for current depressive symptoms plus probable major depressive or dysthymic disorder in the preceding year. Patients were ineligible if they were under 18 years of age, not fluent in English or Spanish, or if practice providers or therapists participating in the interventions were not covered by their insurance. The study was approved by the institutional review boards of RAND and the practices.

Of those completing the screening assessment, 3,918 were potentially eligible, but many left the clinic before the study could check insurance status; 2,417 were available for confirming insurance, and 241 (10\%) had ineligible insurance. Of those who provided written informed consent, 1,356 (70\%) were enrolled; 443 received usual care, with the remaining subjects split between the two quality improvement programs (medication $[\mathrm{N}=$ 424] or therapy [ $\mathrm{N}=489]$ ).

\section{Intervention Conditions}

The quality improvement programs were based on the patient and provider behavior change literature and were implemented by the local managed care organization. The goal of the intervention was to increase the proportion of depressed patients who received appropriate care, defined as either antidepressant medication or psychotherapy. Both quality improvement programs involved 1) institutional commitment in the form of resources to support the intervention model, matched by the study; 2) a local interdisciplinary clinical team trained by the study to provide oversight to intervention implementation, supervise intervention staff, and provide monthly quality review of cases; 3 ) education for local clinicians, provided by the local quality review team; 4) nurse depression specialists, trained by the study, who were available to help with initial clinical assessments and educate patients to facilitate treatment decisions; and 5) toolkits to support these activities, developed by the study and disseminated by the local quality review team and intervention staff. All intervention 
toolkit materials are available on the RAND web site (http:// www.rand.org/organization/health), and all patient materials are available in English and Spanish.

The quality improvement program involving medication provided enhanced resources for supporting medication management that included ongoing access to a depression nurse specialist in the role of case manager for 6-12 months. The quality improvement program involving psychotherapy provided enhanced resources for psychotherapy for depression, including trained local psychotherapists who offered individual or group cognitive behavior therapy $(26,27)$ that included a brief four-session form of cognitive behavior therapy for patients with minor depression. However, patients could also use other practice therapy. Usual care consisted of providing the clinic directors with copies of written practice guidelines for depression in primary care, with no other study assistance. Clinicians and patients in all three arms were free to choose the type of treatment provided or no treatment. Previous work (28) has described adherence to the intervention protocol and changes in the process of care.

\section{Modifications for Substance Abuse}

The nurse specialists were trained to screen for a current substance use disorder and provide that information to the primary care doctor on a simple checklist. The clinician manual included encouragement to screen for a comorbid substance use disorder and discussed options for care. For people with abuse or dependence, the manual recommended referral to a psychiatrist or a comprehensive substance abuse treatment program with a reevaluation in 1-2 months. For people with at-risk drinking, the manual recommended referral to self-help groups and counseling about limiting alcohol use; depression treatment was considered if the patient could maintain sobriety for at least 1 month and had persistent depressive symptoms.

\section{Measures}

We used the Composite International Diagnostic Interview (29) to assess major depression and dysthymia at baseline, 6, and 12 months. Patients were categorized as having a probable depressive disorder if they endorsed any stem item for major depression or dysthymia in the preceding year and were positive for any item in the preceding month as well. Hazardous drinking was measured with the Alcohol Use Disorders Identification Test; we used a cutoff score of 8 out of 40 , which has a sensitivity of $96 \%$ and a specificity of $98 \%$ for hazardous alcohol consumption (30-33). The drug misuse assessment instrument was modified from a validated substance abuse screener (34), and drug misuse was defined as use of either legal or illegal substances without a doctor's prescription, in greater amounts or more often than prescribed, or for a reason other than a doctor's recommendation. Drug categories included cannabis, sedatives and tranquilizers, opiates, cocaine and crack, amphetamines, psychedelics, and inhalants (9).

Each survey assessed antidepressant use and use of specialty counseling, and indicators of medication and psychotherapy treatment were developed. Since both psychotherapy and antidepressants are appropriate treatments for depression, we considered the presence of either during a given 6 -month period as appropriate treatment and pooled the results of the two quality improvement interventions. Previous work indicates that both approaches improved treatment rates as well as clinical outcomes and health-related quality of life $(12,13)$

\section{Subjects}

Table 1 shows the characteristics of all subjects who remained in the study at the 12-month follow-up assessment, with a comparison of those attending a clinic assigned to provide usual care and those attending a clinic providing a quality improvement program. Substance misuse was present in $34 \%$ of the subjects.
The two groups were similar on most characteristics, but subjects in the quality improvement programs were significantly older than subjects in the usual care group and were more likely to be college educated. Within the groups of subjects who did or did not misuse substances, educational status and age did not differ significantly between those in quality improvement programs and those receiving usual care (data not shown). There were fewer female clients with substance misuse in the usual care group than in the quality improvement programs (53\% versus $66 \%)$, $(\mathrm{p}<0.05)$.

\section{Statistical Analyses}

We implemented an analytical approach that is suitable for the analysis of a group-level randomized trial. The group-level randomized trial differs from the more standard patient-level randomized trial in that groups (i.e., clinics), rather than patients, are randomly assigned to the study conditions. All patients attending the same clinic are automatically assigned to the intervention condition that was randomly assigned to their clinic. A patient will be more similar to others at his or her own clinic than to patients at other clinics, since a clinic's patients are not randomly drawn from the population. This results in correlated outcome measures for patients belonging to the same clinic. Statistical analyses that fail to adjust for this correlation could produce spuriously significant results (35). Thus, we employed bias-reduced linearization (36) to estimate robust standard errors for all estimates to correct for the correlation of patients within clinics, although we found this correlation to be very close to zero. The degrees of freedom that were used in all statistical tests are based on the number of practices randomized in the study, which is consistent with group-level randomized trial recommendations (35).

We used multiple logistic regression to test our hypotheses. The models controlled for the following demographic and clinical characteristics: gender, ethnicity, age, marital status, household wealth ranked within age categories (using items modeled after the Health and Retirement Study [37]), educational level, comorbid anxiety disorder, depression diagnosis at baseline, mental and physical health composite scores from the 12-item ShortForm Health Survey (38), substance misuse, intervention status, interaction of substance misuse and intervention status, and study block (matched sets of three clinic clusters). We controlled for covariates that are predictive of outcome as recommended for group-level randomized trials (35).

Standardized predictions (39) of the adjusted rates of depression and use of psychotherapy and medication (treatment process) were computed. The first step in obtaining standardized predictions for our first hypothesis was to use the parameter estimates from the multiple logistic regression model and each individual's observed values for covariates to generate predicted outcome values of being depressed under the scenario that the patients received usual care. To obtain the adjusted percentage of individuals who were depressed among the substance misusers, we then averaged these predictions for substance misusers under the scenario that all substance misusers received usual care. We obtained the adjusted percentage for subjects who did not misuse substances analogously. The approach was repeated using treatment process as the outcome, and was modified accordingly to examine our second hypothesis. Tests of significance were directly derived from the multiple logistic regression model parameters.

In all of our analyses, the data are weighted for the probability of enrollment, attrition, and response to each of the follow-up survey waves at 6 and 12 months. These nonresponse weights were derived using logistic regression in which the probability of completing the survey was modeled as a function of patient demographic factors, clinical indicators, site of treatment, and treatment status. We used multiple imputation for missing data at the item level. We imputed five data sets, averaged the estimates that were obtained from each of the imputed data sets, and adjusted 
TABLE 1. Baseline Characteristics of Depressed Subjects Who Completed a 12-Month Trial During Which They Attended a Clinic Assigned to Offer Usual Care or a Quality Improvement Program

\begin{tabular}{|c|c|c|c|c|c|c|c|c|c|}
\hline \multirow[t]{2}{*}{ Characteristic } & \multicolumn{2}{|c|}{$\begin{array}{l}\text { All Patients } \\
(\mathrm{N}=1,126)\end{array}$} & \multicolumn{2}{|c|}{$\begin{array}{l}\text { Patients Receiving } \\
\text { Usual Care } \\
(\mathrm{N}=374)\end{array}$} & \multicolumn{2}{|c|}{$\begin{array}{c}\text { Patients in a Quality } \\
\text { Improvement Program } \\
(\mathrm{N}=752)\end{array}$} & \multirow[t]{2}{*}{$\mathrm{F}$} & \multirow[t]{2}{*}{$\mathrm{df}$} & \multirow[t]{2}{*}{$\mathrm{p}$} \\
\hline & $\mathrm{N}$ & $\%^{\mathrm{a}}$ & $\mathrm{N}$ & $\%^{\mathrm{a}}$ & $\mathrm{N}$ & $\%^{\mathrm{a}}$ & & & \\
\hline Female & 826 & 70.77 & 257 & 69.36 & 569 & 71.46 & 0.45 & 1,42 & 0.51 \\
\hline \multicolumn{10}{|l|}{ Ethnicity } \\
\hline White & 677 & 56.69 & 219 & 54.65 & 458 & 57.68 & 0.96 & 3,42 & 0.43 \\
\hline Black & 72 & 7.34 & 25 & 9.24 & 47 & 6.42 & & & \\
\hline Hispanic & 300 & 29.71 & 107 & 30.65 & 193 & 29.25 & & & \\
\hline \multirow[t]{2}{*}{ Other } & 77 & 6.26 & 23 & 5.46 & 54 & 6.66 & & & \\
\hline & Mean & SD & Mean & SD & Mean & SD & & & \\
\hline Age (years) & 43.7 & 14.63 & 42.18 & 13.82 & 44.43 & 14.96 & 4.99 & 1,42 & 0.04 \\
\hline Net worth rank & 0.50 & 0.28 & 0.49 & 0.28 & 0.51 & 0.28 & 0.57 & 1,42 & 0.46 \\
\hline \multicolumn{10}{|l|}{ 12-Item Short-Form Health Survey scores } \\
\hline Physical scale & 44.99 & 11.68 & 44.55 & 11.91 & 45.21 & 11.56 & 0.66 & 1,42 & 0.42 \\
\hline \multirow[t]{2}{*}{ Mental scale } & 35.75 & 10.83 & 36.35 & 11.2 & 35.45 & 10.64 & 1.17 & 1,42 & 0.29 \\
\hline & $\mathrm{N}$ & $\%^{\mathrm{a}}$ & $\mathrm{N}$ & $\%^{\mathrm{a}}$ & $\mathrm{N}$ & $\%^{\mathrm{a}}$ & & & \\
\hline Married & 638 & 54.39 & 218 & 53.04 & 420 & 55.05 & 0.32 & 1,42 & 0.58 \\
\hline Education & & & & & & & 3.17 & 3,42 & 0.04 \\
\hline Less than high school & 171 & 18.52 & 68 & 20.04 & 103 & 17.79 & & & \\
\hline High school graduates & 306 & 29.69 & 121 & 33.30 & 185 & 27.94 & & & \\
\hline Some college & 384 & 31.99 & 116 & 31.67 & 268 & 32.15 & & & \\
\hline College or more & 265 & 19.79 & 69 & 14.99 & 196 & 22.13 & & & \\
\hline \multicolumn{10}{|l|}{ Number of chronic health conditions } \\
\hline None & 235 & 22 & 74 & 20.75 & 161 & 22.61 & 0.15 & 3,42 & 0.94 \\
\hline 1 & 258 & 23.94 & 80 & 24.08 & 177 & 23.88 & & & \\
\hline 2 & 235 & 20.23 & 76 & 20.77 & 160 & 19.96 & & & \\
\hline$\geq 3$ & 398 & 33.83 & 144 & 34.4 & 254 & 33.55 & & & \\
\hline \multicolumn{10}{|l|}{ Psychopathology } \\
\hline Anxiety & 519 & 43.88 & 164 & 43.66 & 354 & 43.99 & 0.009 & 1,42 & 0.93 \\
\hline Major depressive disorders & & & & & & & 1.78 & 3,42 & 0.17 \\
\hline Major depressive and dysthymic disorders & 140 & 11.91 & 35 & 11.17 & 105 & 12.28 & & & \\
\hline Major depressive disorder only & 504 & 41.17 & 150 & 37.57 & 354 & 42.92 & & & \\
\hline Dysthymic disorder & 33 & 2.7 & 8 & 2.03 & 25 & 3.03 & & & \\
\hline Symptoms or lifetime history of disorder & 449 & 44.22 & 181 & 49.23 & 268 & 41.78 & & & \\
\hline \multicolumn{10}{|l|}{ Substance use ${ }^{b}$} \\
\hline Any substance misuse $\mathrm{b}^{\mathrm{b}}$ & 361 & 33.95 & 116 & 34.67 & 245 & 33.62 & 0.10 & 1,42 & 0.76 \\
\hline Hazardous drinking & 110 & 10.88 & 37 & 11.83 & 73 & 10.45 & 0.36 & 1,42 & 0.56 \\
\hline Prescription drug misuse & 207 & 18.92 & 64 & 17.68 & 143 & 19.5 & 0.46 & 1,42 & 0.51 \\
\hline All illicit drug use & 121 & 11.53 & 39 & 12.4 & 81 & 11.12 & 0.31 & 1,42 & 0.58 \\
\hline Cannabis & 111 & 10.6 & 36 & 11.14 & 75 & 10.35 & 0.13 & 1,42 & 0.72 \\
\hline
\end{tabular}

a Data are weighted for the probability of enrollment, attrition, and response to each of the follow-up survey waves at 6 and 12 months.

b Number of nonmissing observations $=1,061$.

standard errors for uncertainty due to imputation $(40,41)$. Outcome variables were not imputed.

\section{Results}

Among enrollees in usual care, participants with comorbid substance misuse did not statistically significantly differ from those with no substance misuse with respect to having probable depressive disorder, psychotherapy or antidepressant use, or overall appropriate treatment at baseline, 6, and 12 months (Table 2), with the exception that substance misusers received more overall appropriate treatment than those who did not misuse substances at 6 months. While clients with substance misuse tended to have a higher rate of psychotherapy use at 6 months than was seen among those with no substance misuse, this difference did not reach significance.

Among clients with comorbid substance misuse, those attending a clinic providing one of the two quality improvement programs had improved depression outcomes at 12 months than did those receiving usual care and had significantly greater antidepressant use at 6 months but not at 12 months (Table 3 ). The quality improvement program did not increase rates of psychotherapy among patients with substance misuse.

Among those without substance misuse, the quality improvement programs improved depression outcomes at 6 months, although the improvement decreased by 12 months (Table 3). Among those without substance misuse, the quality improvement programs were also associ- 
WATKINS, PADDOCK, ZHANG, ET AL.

TABLE 2. Clinical Outcomes for Depressed Subjects Attending a Clinic Assigned to Provide Usual Care, by Substance Misuse Status $^{\mathrm{a}}$

\begin{tabular}{|c|c|c|c|c|c|c|c|c|}
\hline \multirow[b]{3}{*}{ Outcome or Pattern of Care } & \multicolumn{3}{|c|}{ Patients Without Substance Misuse } & \multicolumn{3}{|c|}{ Patients With Substance Misuse } & & \\
\hline & \multirow[b]{2}{*}{$\mathrm{N}$} & \multicolumn{2}{|c|}{ Variable Present } & \multirow[b]{2}{*}{$\mathrm{N}$} & \multicolumn{2}{|c|}{ Variable Present } & \multicolumn{2}{|c|}{ Analysis } \\
\hline & & $\%$ & $95 \% \mathrm{Cl}$ & & $\%$ & $95 \% \mathrm{Cl}$ & $t(d f=42)$ & $\mathrm{p}$ \\
\hline \multicolumn{9}{|l|}{ Baseline } \\
\hline Any psychotherapy & 785 & 24.1 & 18.7-29.5 & 402 & 31.9 & 23.9-39.9 & 0.11 & 0.28 \\
\hline Any antidepressant use & 785 & 32.2 & $26.7-37.7$ & 402 & 34.4 & $26.3-42.6$ & -0.19 & 0.85 \\
\hline Either psychotherapy or antidepressant use & 785 & 40.9 & $34.9-46.9$ & 402 & 49.3 & $40.3-58.3$ & 0.95 & 0.35 \\
\hline \multicolumn{9}{|l|}{6 months } \\
\hline Probable depressive disorder diagnosis & 713 & 46.8 & $40.4-53.2$ & 366 & 56.0 & $44.1-61.3$ & 0.61 & 0.54 \\
\hline Any psychotherapy & 715 & 21.6 & $16.1-27.1$ & 367 & 32.4 & $23.6-41.3$ & 1.85 & 0.08 \\
\hline Any antidepressant use & 713 & 30.1 & $24.3-45.5$ & 366 & 35.7 & $27.8-43.6$ & 0.40 & 0.69 \\
\hline Either psychotherapy or antidepressant use & 713 & 39.2 & $32.9-45.5$ & 366 & 52.1 & $43.0-61.2$ & 2.11 & 0.05 \\
\hline \multicolumn{9}{|l|}{12 months } \\
\hline Probable depressive disorder diagnosis & 698 & 45.6 & $39.5-52.8$ & 360 & 60.0 & $51.2-68.7$ & 1.41 & 0.17 \\
\hline Any psychotherapy & 699 & 18.3 & $13.2-23.5$ & 361 & 26.0 & $17.0-34.9$ & 1.22 & 0.23 \\
\hline Any antidepressant use & 698 & 32.1 & $26.4-37.9$ & 360 & 30.2 & $21.1-39.3$ & -0.71 & 0.49 \\
\hline Either psychotherapy or antidepressant use & 698 & 39.6 & $33.4-45.9$ & 360 & 42.6 & $32.8-52.4$ & 0.17 & 0.86 \\
\hline
\end{tabular}

${ }^{a}$ Data are adjusted for covariates and treatment status and weighted to correct for the probability of enrollment, attrition, and survey nonresponse in the full sample of screened, eligible patients.

ated with increased treatment utilization at 6 months for all three treatment process measures (Table 3), although at 12 months the only significant difference between the quality improvement and usual care groups was in psychotherapy use.

In order to further explore whether the pooled quality improvement programs differentially impacted patients with and without substance misuse, we looked at whether the interaction between intervention status and substance misuse predicted depression outcomes and patterns of care at 6 and 12 months. Of the eight measures of process and outcomes examined at 6 and 12 months, an interaction between intervention and substance misuse was statistically significant for only one measure-any use of psychotherapy services in the first 6 months-which showed a greater increase under the intervention relative to usual care for those without comorbid substance abuse $(\mathrm{p}<0.05)$. Thus, there is little consistent evidence for a differential intervention-by-comorbidity effect on process or outcomes.

\section{Discussion}

Substance misuse is common among individuals with depression seen in primary care settings. In our study group, one-third of patients with a probable depressive disorder also had comorbid substance misuse. Under usual care conditions, depressed patients with substance misuse had an increased probability of ongoing depression at both the 6- and 12-month follow-up evaluations, despite higher rates of treatment relative to individuals without substance misuse. This extends previous findings that cooccurring substance use disorders are associated with depression and with poorer depression treatment outcomes $(4-6,21)$ and is consistent with the general beliefs that 1) substance use may induce and prolong depressive disorders, 2) the two disorders share common risk factors, and 3) depression may promote substance misuse. However, it does not support our hypothesis that under usual care, cooccurring substance misuse would be associated with lower rates of treatment. This may be because in our study the substance misusers were sicker or because they were more likely to have received specialty care.

We also found that in depressed patients with comorbid substance misuse, quality improvement programs significantly reduced the likelihood of probable depressive disorders at the 12-month follow-up evaluation. Rates of treatment for individuals with comorbid substance misuse increased at both the 6- and 12-month follow-up evaluations, although only changes in antidepressant use reached statistical significance at 6 months. These findings paralleled those for depressed patients without substance misuse and suggest that quality improvement interventions can benefit a broad range of individuals, including individuals with substance misuse or medical comorbidity (14). The pattern of change over time also suggests that there is a continuing main effect of the intervention and that the effects persist. This is somewhat surprising, given that quality improvement programs do not focus on treating every patient but rather foster conditions that increase the likelihood of treatment for a pool of at-risk patients and typically improve treatment rates only modestly.

We found no consistent evidence for a differential program-by-comorbidity effect, except for a suggestion of greater increase in psychotherapy among individuals with no substance misuse. This was contrary to our initial hypothesis that providers would be more likely to provide psychotherapy than medication, since behavioral treatments carry little risk to the patient and can be initiated even without a formal diagnosis of depression. There are a number of possible explanations for this finding. Providers may have concerns about patient compliance with psychotherapy or the effectiveness of psychotherapy in substance misusers. Alternatively, patients with sub- 
TABLE 3. Clinical Outcomes at 6 and 12 Months for Depressed Subjects Attending a Clinic Assigned to Offer Usual Care or a Quality Improvement Program, by Substance Misuse Status ${ }^{\mathrm{a}}$

\begin{tabular}{|c|c|c|c|c|c|c|}
\hline \multirow[b]{3}{*}{ Group and Outcome } & \multicolumn{4}{|c|}{ Treatment Provided by Clinic } & & \\
\hline & \multicolumn{2}{|c|}{ Usual Care } & \multicolumn{2}{|c|}{$\begin{array}{c}\text { Quality Improvement } \\
\text { Program }\end{array}$} & \multicolumn{2}{|c|}{ Analysis } \\
\hline & $\%$ & $95 \% \mathrm{Cl}$ & $\%$ & $95 \% \mathrm{Cl}$ & $t(d f=42)$ & $\mathrm{p}$ \\
\hline \multicolumn{7}{|l|}{ Depressed patients with substance misuse } \\
\hline \multicolumn{7}{|l|}{6 months $(N=367)$} \\
\hline Probable depressive disorder & 56.0 & $47.5-64.5$ & 45.3 & $38.9-51.6$ & -1.64 & 0.11 \\
\hline Any psychotherapy & 32.4 & $23.6-41.3$ & 38.8 & $32.6-45.0$ & 1.26 & 0.22 \\
\hline Any antidepressant use & 35.7 & $27.8-43.6$ & 47.4 & $41.2-53.7$ & 2.23 & 0.04 \\
\hline Either psychotherapy or antidepressant use & 52.1 & $43.0-61.2$ & 57.1 & $50.8-63.4$ & 0.91 & 0.37 \\
\hline \multicolumn{7}{|l|}{12 months $(\mathrm{N}=361)$} \\
\hline Probable depressive disorder & 60.0 & $51.2-68.7$ & 46.8 & $40.3-53.3$ & -2.40 & 0.03 \\
\hline Any psychotherapy & 26.0 & $17.0-34.9$ & 30.0 & $24.0-35.9$ & 0.65 & 0.52 \\
\hline Any antidepressant use & 30.2 & $21.1-39.3$ & 39.0 & $32.8-45.2$ & 1.60 & 0.17 \\
\hline Either psychotherapy or antidepressant use & 42.6 & $32.8-52.4$ & 46.2 & $40.0-52.5$ & 0.49 & 0.63 \\
\hline \multicolumn{7}{|l|}{ Depressed patients without substance misuse } \\
\hline \multicolumn{7}{|l|}{6 months $(\mathrm{N}=715)$} \\
\hline Probable depressive disorder & 46.8 & $40.4-53.2$ & 36.7 & $32.3-41.1$ & -2.30 & 0.03 \\
\hline Any psychotherapy & 21.6 & $16.1-27.1$ & 38.6 & $34.2-42.9$ & 4.07 & 0.0002 \\
\hline Any antidepressant use & 30.1 & $24.3-35.9$ & 39.2 & $35.0-43.3$ & 2.48 & 0.02 \\
\hline Either psychotherapy or antidepressant use & 39.2 & $32.9-45.5$ & 53.0 & $48.5-57.5$ & 3.79 & 0.0004 \\
\hline \multicolumn{7}{|l|}{12 months $(\mathrm{N}=699)$} \\
\hline Probable depressive disorder & 45.6 & $39.5-52.8$ & 38.4 & $34.1-42.8$ & -1.48 & 0.15 \\
\hline Any psychotherapy & 18.3 & $13.2-23.5$ & 26.0 & $22.1-29.8$ & 2.02 & 0.05 \\
\hline Any antidepressant use & 32.1 & $26.4-37.9$ & 35.5 & $31.3-39.6$ & 0.79 & 0.43 \\
\hline Either psychotherapy or antidepressant use & 39.6 & $33.4-45.9$ & 43.2 & $38.8-47.7$ & 0.79 & 0.43 \\
\hline
\end{tabular}

${ }^{a}$ Data are adjusted for covariates and treatment status and weighted to correct for the probability of enrollment, attrition, and survey nonresponse in the full sample of screened, eligible patients.

stance misuse may have a preference for medication. While only suggestive, this finding suggests important areas for future research.

It is possible that some of the depressive symptom improvement among those within the quality improvement programs was not due to increased rates of treatment but to reduced alcohol and drug use. Both quality improvement interventions recommended that primary care providers counsel nondependent patients to decrease alcohol use and refer dependent patients to either a psychiatrist or specialty substance abuse treatment. Brief interventions are an effective method of addressing alcohol use disorders in nondependent patients, reducing consumption by up to $30 \%$ (42). This includes individuals like those in this study who were identified by opportunistic screening in primary care settings and for whom recommended care was a single counseling session with a subsequent follow-up visit (43). Substance abuse treatment can also reduce the level of depressive symptoms (17). However, while reduced alcohol and drug use may explain some of the improvement in rates of probable depressive disorder, it is unlikely to explain all of it. The most common type of substance misuse in our study group was sedative and tranquilizer misuse, which is not commonly associated with a substance-induced depressive disorder (9). Future studies should examine the extent to which improvements in depression might be related to improvements in substance misuse.

It should be noted that the improved outcomes we saw were achieved in a relatively broadly defined group of depressed patients, since only $55 \%$ of them had depressive disorder at 1 year, with the rest having minor depression that increased their risk for a depressive disorder. Similarly, the intervention approach did not necessarily involve providing treatment immediately but rather involved considering the patient's condition and negotiating a treatment strategy. In the case of an individual with substance misuse, this might mean waiting for greater diagnostic clarity and may account for the outcomes in this group being statistically significant at 12 months. Both of these points highlight the strength of the external validity of the quality improvement programs.

The quality improvement programs used in Partners in Care were roughly equally effective in improving depression outcomes for patients with and without comorbid substance misuse, even though such comorbidity increased patients' risks for poorer outcomes. Because substance use outcomes and treatment were not measured at 6 and 12 months, the impact of the intervention on substance use outcomes is not known and is a limitation of the study. Future quality improvement programs for depression should address this limitation. In addition, quality improvement programs to increase recognition and treatment of substance misuse in primary care and to address comorbid substance misuse and depression should be developed, and the impact on both substance use and depression outcomes should be studied.

There are several additional limitations to the study. It is difficult to diagnose depression in patients with substance misuse, and some of the individuals included in the study may have had a substance-induced depressive disorder. 
Substance intoxication and withdrawal can cause many of the symptoms of depression, such as sleep difficulties, depressed mood, and fatigue. In addition, we relied on patient self-report to measure their use of alcohol and other illicit substances. Underreporting of substance use may have led us to incorrectly classify some individuals. On the other hand, we sampled patients consecutively, which may have resulted in oversampling patients with more clinic use, who were more ill, or who had more problematic substance use problems. The study took place in managed primary care settings, which limits generalizability to other non-managed care settings. However the organizations were diverse and included public and private and urban and rural settings; the patients were also clinically and demographically diverse. We were also limited by the study group size, which included only 361 individuals with comorbid substance misuse.

Received July 28, 2004; revisions received Oct. 28, 2004, and Jan. 12, 2005; accepted Feb. 14, 2005. From the RAND Corporation and the UCLA/NPI Health Services Research Center, Los Angeles. Address correspondence and reprint requests to Dr. Watkins, RAND Corporation, 1776 Main St., P.O. Box 2138, Santa Monica, CA 90407-2138.

This work was supported by the RAND Health Program (Drs. Watkins and Paddock), NIMH grant R01 MH-61570, and UCLA Center Grant P30 MH-068639 (Dr. Wells and Ms. Zhang).

The authors thank Maureen Carney, M.S., for coordination of Partners in Care follow-up; Barbara Levitan, B.A., for oversight of the survey work; Bernadette Benjamin, M.S., for programming support; and Naihua Duan, Ph.D., and Lingqi Tang, Ph.D., for statistical consultation. The authors also thank the clinicians and patients who contributed their time and efforts to this study.

The following managed care organizations and their associated behavioral health organizations participated in the Partners in Care trial: Allina Medical Group (Twin Cities, Minn.), Patuxent Medical Group (Patuxent, Md.), Humana Health Care Plans (San Antonio, Tex.), MedPartners (Los Angeles), PacifiCare of Texas (San Antonio), Valley-Wide Health Services (Alamosa, Colo.), Alamo Mental Health Group (San Antonio, Tex.), San Luis Valley Mental Health/Colorado Health Networks (Alamosa, Colo.), and Magellan/GreenSpring Behavioral Health (Patuxent, Md.).

\section{References}

1. Kirchner JE, Curran GM, Thrush CR, Owen RR, Jortney JC, Booth BM: Addictions services: depressive disorders and alcohol dependence in a community population. Community Ment Health J 2002; 39:361-373

2. Cornelius JR, Salloum IM, Day NL, Thase ME, Haskett RF, Daley DC, Jones-Barlock A, Upsher C, Perel JM: Fluoxetine versus placebo in depressed alcoholic cocaine abusers. Psychopharmacol Bull 1998; 34:117-121

3. Schmitz J, Averill MP, Stotts AL, Moeller FG, Rhoades HM, Grabowski J: Fluoxetine treatment of cocaine-dependent patients with major depressive disorder. Drug Alcohol Depend 2001; 63:207-214

4. Worthington J, Fava M, Agustin C, Alpert J, Nierenberg AA, Pava JA, Rosenbaum JF: Consumption of alcohol, nicotine, and caffeine among depressed outpatients: relationship with response to treatment. Psychosomatics 1996; 37:518-522

5. Brown C, Schulberg HC: Diagnosis and treatment of depression in primary medical care practice: the application of research findings to clinical practice. J Clin Psychol 1998; 54:303-314

6. Carroll KM, Power ME, Bryant K, Rounsaville BJ: One-year follow-up status of treatment-seeking cocaine abusers: psycho- pathology and dependence severity as predictors of outcome. J Nerv Ment Dis 1993; 181:71-79

7. Grant BF: Comorbidity between DSM-IV drug use disorders and major depression: results of a national survey of adults. J Subst Abuse 1995; 7:481-497

8. Grant BF, Harford TC: Comorbidity between DSM-IV alcohol use disorders and major depression: results of a national survey. Drug Alcohol Depend 995; 39:197-206

9. Roeloffs CA, Wells KB, Ziedonis D, Tang L, Unützer J: Problem substance abuse among depressed patients in managed primary care. Psychosomatics 2002; 43:405-412

10. Watkins KE, Burnam A, Kung FY, Paddock S: National survey of care for persons with co-occurring mental and substance use disorder. Psychiatr Serv 2001; 52:1062-1068

11. The NSDUH Report: National Survey on Drug Use and Health. Rockville, Md, Substance Abuse and Mental Health Services Administration, Office of Applied Studies, 2004

12. Wells KB, Sherbourne C, Schoenbaum M, Duan N, Meredith L, Unützer J, Miranda J, Carney MF, Rubenstein LV: Impact of disseminating quality improvement programs for depression in managed primary care. JAMA 2000; 238:212-220

13. Wells K, Sherbourne C, Schoenbaum M, Ettner S, Duan N, Miranda J, Unützer J, Rubenstein L: Five-year impact of quality improvement for depression: results of a group-level randomized controlled trial. Arch Gen Psychiatry 2004; 61:378-386

14. Koike AK, Unützer J, Wells KB: Improving the care for depression in patients with comorbid medical illness. Am J Psychiatry 2002; 159:1738-1745; correction, 2003; 160:204

15. Sherbourne CD, Weiss R, Duan N, Bird CE, Wells KB: Do the effects of quality improvement for depression care differ for men and women? results of a group-level randomized controlled trial. Med Care 2004; 42:1186-1193

16. Depression in Primary Care, vols 1, 2: AHCPR Publications 930440, 93-0551. Rockville, Md, Agency for Healthcare Research and Quality, Depression Guidelines Panel, 1993

17. Sacks S, Ries RK: Substance Abuse Treatment for Persons With Co-Occurring Disorders: Treatment Improvement Protocol (TIP) Series 42. DHHS Publication SMA 05-3922. Rockville, Md, Substance Abuse and Mental Health Administration, 2005, p 102

18. Mueser KT, Noordsy DL, Drake RE, Fox L: Integrated Treatment for Dual Disorders: A Guide to Effective Practice. New York, Guilford, 2003

19. Oslin DW, Katz IR, Edell WS, Ten Have TR: Effects of alcohol consumption on the treatment of depression among elderly patients. Am J Geriatr Psychiatry 2000; 8:215-220

20. Curran GM, Booth BM, Kirchner JE: The role of depressive symptomatology and the return to substance use, in Conference Proceedings: Complexities of Co-Occurring Conditions: Harnessing Services Research to Improve Care for Mental, Substance Use, and Medical/Physical Disorders. Washington, DC, US Department of Health and Human Services, 2004, poster 10

21. Nunes EV, Levin FR: Treatment of depression in patients with alcohol or other drug dependence. a meta-analysis. JAMA 2004; 291:1887-1896

22. Brown RA, Ramsey SE: Addressing co-morbid depressive symptomatology in alcohol treatment. Prof Psychol Res Pr 2000; 31: $418-422$

23. Scott J, Gilvarry E, Farrell M: Managing anxiety and depression in alcohol and drug dependence. Addict Behav 1998; 23:919931

24. Brown JB, Shye D, McFarland B: The paradox of guideline implementation: how AHCPR's depression guideline was adapted at Kaiser Permanante Northwest Region. Jt Comm J Qual Improv 1995; 21:5-21

25. Wells KB: The design of Partners in Care: evaluating the cost effectiveness of improving care for depression in primary care. Soc Psychiatry Psychiatr Epidemiol 1999; 34:20-29 
26. Munoz RF, Miranda J: Group Therapy for Cognitive Behavioral Treatment of Depression: San Francisco General Hospital Depression Clinic 1986. Santa Monica, Calif, RAND Corp, 2000

27. Munoz RF, Aguilar-Gaxiola S, Guzman J: Manual de Terapia de Grupo para el Tratamiento Cognitivo-conductal de Depression: Hospital General de San Francisco, Clinica de Depresion 1986. Santa Monica, Calif, RAND Corp, 2000

28. Rubenstein LV, Jackson-Triche $M$, Unützer J, Miranda J, Minnium K, Pearson ML, Wells KB: Evidence-based care for depression in managed primary care practices. Health Aff 1999; 18: 89-105

29. World Health Organization: Composite International Diagnostic Interview (CIDI), version 2.1. Geneva, WHO, 1997

30. Reid M, Fiellin DA, O'Connor PG: Hazardous and harmful alcohol consumption in primary care. Arch Intern Med 1999; 159: 1681-1689

31. Saunders JB, Aasland OG: World Health Organization Collaborative Project on the Identification and Treatment of Persons With Harmful Alcohol Consumption. Geneva, WHO, 1987

32. Saunders JB, Aasland OG, Babor TF, de la Fuente JR, Grant M: Development of the Alcohol Use Disorders Identification Test (AUDIT): WHO Collaborative Project on Early Detection of Persons With Harmful Alcohol Consumption, II. Addiction 1993; 88:791-804

33. Conigrave KM, Hall WE, Saunders JB: The AUDIT Questionnaire: choosing a cut-off score. Addiction 1995; 90:1349-1356
34. Rost K, Burnam MA, Smith GR: Development of screeners for depressive disorders and substance disorder history. Med Care 1993; 31:189-200

35. Murray DM: Design and Analysis of Group-Randomized Trials. Oxford, UK, Oxford University Press, 1998

36. Bell RM, McCaffrey DF: Bias reduction in standard errors for linear regression with multi-stage samples. Surv Methodol 2002; 28:169-179

37. Northwehr F, Stump T: Health-promoting behaviors among adults with type 2 diabetes: findings from the Heath and Retirement Study. Prev Med 2000; 30:407-414

38. Ware J Jr, Kosinski M, Keller SD: A 12-item short-form health survey: construction of scales and preliminary tests of reliability and validity. Med Care 1996; 34:220-233

39. Graubard BI, Korn EL: Predictive margins with survey data. Biometrics 1999; 55:652-659

40. Rubin DB: Multiple Imputation for Nonresponse in Surveys. New York, John Wiley \& Sons, 1986

41. Schafer JL: Analysis of Incomplete Multivariate Data. London, Chapman \& Hall, 1997

42. Wilk Al, Jensen NM, Havighurst TC: Meta-analysis of randomized control trials addressing brief interventions in heavy alcohol drinkers. J Gen Intern Med 1997; 12:274-283

43. Moyer A, Finney JF, Swearingen CE, Vergun P: Brief interventions for alcohol problems: a meta-analytic review of controlled investigations in treatment-seeking and non-treatmentseeking populations. Addiction 2002; 97:279-292 